\title{
Fiscal Foundations of Price Stability in Open Economies
}

\author{
by Christopher A. Sims
}

September 1997

This draft is preliminary and incomplete. (C) 1997 by Christopher A. Sims. Single copies for personal use and multiple copies for educational and research purposes, are allowed, so long as this copyright notice is included in the copies, no changes are made in the document, and, in the case of multiple copies, the copies are distributed without any charge, even to reimburse the expenses of copying. 


\section{Introduction}

Large, economically advanced states issue public debt that is anonymously held, publicly traded in liquid markets, and regarded as essentially free of default risk. At the same time, they have monetary systems in which a central bank holds, as backing for its monetary liabilities, mainly the country's own interest-bearing public debt. These aspects of monetary and fiscal systems arose jointly, are mutually dependent, and are a source of substantial benefits to the states and their citizens.

Macroeconomic theory has until recently not paid much attention to the historically apparent close links of monetary and fiscal policy and institutions. Textbooks display models in which the only stock of government liabilities treated explicitly is non-interest-bearing high-powered money. Government debt and the intertemporal government budget constraint are often treated as a recursive appendage to the main theory, or not treated at all. The fact that the central bank owns government debt that backs its monetary liabilities is treated as an accounting fiction, with the theory consolidating central bank and fiscal authority, treating "government debt" as debt "in the hands of the public." The student could easily get the idea from such expositions - indeed I believe most do get the idea - that the stock of government debt has nothing to do with price determination and that central bank holdings of government debt are not really "reserves" in any economically meaningful sense.

An important and growing stream of recent macroeconomic literature has, however, explored the interconnections of fiscal and monetary policy and institutions. Sargent and Wallace [1981] and Aiyagari and Gertler [1985] explained that theories that ignored fiscal policy were incomplete and that ignoring fiscal-monetary interactions could lead to policy errors. These papers retained the viewpoint that price determination was mainly a matter of monetary policy, however. More recent literature, of which some examples are Leeper [1991], Sims [1988], Sims [1994], Woodford [1994], Woodford [1995], and Schmitt-Grohë and Uribe [1997], has pursued the implications of fiscal-monetary interactions more radically. ${ }^{1}$ These papers give fiscal policy at least a co-equal role with monetary policy in determining prices.

This new theory is not simply tracing out the logic of practically remote special cases; it is developing a way of looking at fiscal and monetary policy that is better suited to modern institutions and policy issues. Indeed, it sometimes appears that the theory is barely keeping up with the policy questions we are encountering. Reserve deposits, which in 1959 made up over $35 \%$ of the monetary base in the US, are now less than 10\%. The Bank of Canada has eliminated reserve requirements and has deposits from banks amounting to only about $3 \%$ of its outstanding notes. It seems possible that "smart cards" that carry electronic charges of purchasing power could displace a substantial part of the demand for currency. Does the fact that high-powered

1 As Woodford [1994] observed, the key point that recognition of the government budget constraint implies price determinacy even with a nominal-interest-rate-pegging policy had been recognized in a few papers even earlier. [get refs] 
money is becoming less closely linked to the volume of transactions balances imply cause for concern about the stability of the price level? In the old theoretical framework, it would seem to; in the new framework it is clear that there is no cause for concern.

This paper aims to develop a theory that applies to a situation where there may be different numbers of monetary and fiscal authorities. The planned European Monetary Union is to produce a single central bank that operates in the context of persistently distinct country fiscal authorities. It has been recognized that this could create problems, and the EMU treaties therefore pose strict fiscal conditions for entry into the union and require that fiscal policy of member states be monitored by the European Central Bank (ECB). Few existing models can explain why fiscal coordination could create problems, however. Indeed some economists think of these fiscal rules as a secondary issue, believing that so long as the ECB maintains a responsible monetary policy, preventing rapid monetary growth or raising interest rates strongly and promptly when inflation appears, that prices will perforce remain stable and government fiscal policies will not matter, as predicted by the standard modeling approach. But there are reasons for concern about fiscal and monetary policy coordination in the EMU, and we need a model that lets us discuss them sensibly.

Currency-board-like monetary regimes, like those of Hong Kong, Argentina, and Singapore, replace the holding of domestic government debt as backing for currency by the holding of a foreign, stable-currency country's debt as backing. There is always a question, however, of how well and permanently such an arrangement insulates monetary from fiscal policy, as well as a question of whether such an arrangement is a good idea, and the new fiscal perspective on price level determination provides a framework for thinking about these issues.

\section{The Origin and Function of Default-Free, Liquid Government Debt}

In Europe until about 300 years ago, government debt was not anonymously held, was not liquid, and was not default free. The kings of England and France borrowed directly from specific individuals or groups, created special forms of security to issue in connection with particular borrowings, and then with some regularity defaulted on particular debt obligations. In England, this pattern ended with the Revolution of 1688. At nearly the same time as this change in the nature of public debt securities, in 1694, the Bank of England was created - in what was seen initially as an essentially fiscal act. A group of wealthy individuals lent a large sum of money to the new Protestant king and were in turn allowed to create an institution to hold the debt that would have banking powers. Though public debt itself did not trade at first, shares in the Bank of England did trade. In France, the corresponding changes came considerably later, and it has been argued that the English precocity in this respect was a source of England's military power and bellicosity at the time.

The need for a kind of default on government debt did not disappear in England with these late- $17^{\text {th }}$ century innovations. About 100 years later, in 1797 under the pressure of wartime finance, the Bank of England suspended redemption of its notes for gold. But while this had the effect of a partial default, it no doubt had less effect on the willingness of the public to hold government debt than the old royal pattern of reneging on individual creditors. Individuals were 
exposed only to the aggregate default risk, not to that plus additional uncertainty over which creditors were to be singled out to absorb the cost. ${ }^{2}$

The decline in risk of outright default became possible only because governments were moving away from precious-metal backed money and debt, and toward a true fiat money system. By this I mean a system in which government securities were not promises to pay in the future a fixed amount of gold or other real commodity, but instead were essentially promises to pay only more government paper. When its debt is denominated in gold, the government can reach a state in which its primary surplus (excess of revenues over expenditures, not counting interest expenses), though expected to stay positive, is not expected to be large enough to cover its existing obligations. It will then not be able to borrow, except perhaps by offering new lenders priority over old ones in case surpluses fall short. But this would be precisely a move back toward the old royal system, with creditors being treated differently during default. Even a government with a very substantial primary surplus could be forced to outright default, if its debt service burden rose to a sustained level above its level of primary surpluses. Since the default would occur in the face of positive primary surpluses, there would be a "liquidation value" to be split up among creditors. This would require decisions about priority, if not along the lines of the old kings' creditor-specific defaults, still along some lines that would generate uncertainty, negotiation costs, or both.

On the other hand, when government debt is only a promise to pay more government debt, as it is in a fiat monetary-fiscal system, there is no possibility of outright default being necessary so long as the primary surplus remains positive. Whatever the level of future primary surpluses, government debt represents a claim on them. Additional government debt simply smoothly dilutes the claims of existing government debt. Thus the new debt always has some value so long as there is any prospect that future revenues will exceed expenditures, and there is no need to give different treatment to different classes of creditors. These results from the recent literature will be explained below in the theoretical sections of this paper.

Whether or not it is important that note-issuing banks hold government debt as reserves depends on institutional details. In the US now, the Treasury could not freely create new interestbearing debt to absorb a sudden decline in the demand for non-interest-bearing high-powered money. There are legal limitations on the amount of outstanding interest-bearing debt that are close to binding even for normal year-to-year variations in the government budget. The limits are regularly changed, but by a legislative process that takes considerable time. It is thus important that there is a stock of government debt already in existence, held by the Federal Reserve Banks, that could be sold to absorb a sudden decline in the demand for money without requiring legislative action. Under a different institutional arrangement, and indeed in the US in an earlier era, it might be possible to create large amounts of debt quickly in the face of a shift in portfolio demand. [Davis [1936] describes an episode under Grover Cleveland's presidency in the US in which a sudden drain on US gold stocks was met by rapid creation and sale of new government

${ }^{2}$ For the final version of this paper, I intend to a look a little further into this. It would be interesting to know how much, if any, loss holders of government debt suffered from this early suspension of specie payment. 
debt. ${ }^{3}$ Even at that time, though, there was controversy over whether Cleveland had exceeded his powers.

Freeing government debt from a metallic standard makes it something like equity in the flow of future primary surpluses. This makes outright bankruptcy of the government a remote possibility and therefore makes it easier to borrow at times of crisis. At the same time, freeing the monetary system from a metallic standard and the need to keep reserves of gold or silver has the standard efficiency advantages that it replaces inefficient stashes of useful commodities with paper reserves that have no efficiency cost. It also has the advantage that it allows the monetary authority to prevent disturbances to the supply and demand of the metal standard from impinging on the price level.

These advantages may explain why monetary systems take the form we see today in large, advanced countries. Can the advantages be maintained in the transition to a common currency, as now planned in the EMU? This is the question that underlies the debate over fiscal rules for the Union.

\section{Implications for EMU and Currency Board Regimes}

While the remaining sections of this paper aim to support the theory it proposes with a variety of mathematical models, it is not difficult to understand the basic ideas asserted by the theory. It may be worthwhile, therefore, to give an indication of how the theory applies to some recent policy discussions before plunging in to the mathematics.

The core of the theory is the idea that fiat money, the kind we see for the most part in modern economies, should be thought of as backed by interest-bearing government debt. This means in turn that the price level should be thought of as determined by the relation between the nominal value of all outstanding government liabilities, on the one hand, and the country's likely level of future fiscal effort and capacity, on the other.

One simple model of the EMU treats it as a single central bank, conducting open market operations in a single, homogeneous type of government debt, but with a collection of independent fiscal authorities issuing the government debt. From this point of view, it is clear why there is a concern with fiscal coordination. The price level in such an EMU would be determined by the ratio of total outstanding debt to total outstanding primary surpluses of all countries in the EMU. A single country issuing debt without any intention of increased primary surpluses in the future to back the debt still generates inflation, but the inflationary effect is diluted by the fact that each country's debt is only a small part of the total. In effect, part of the increased debt is backed by the taxes of other countries. Penalties and institutional controls are needed to prevent individual countries from taking advantage of the possibility of permanently shifting tax burdens on to other countries.

The required controls appear more drastic, though, than what is actually contemplated for the EMU. So long as the EMU does not have a central fiscal authority capable of directly taxing citizens of a country that is in fiscal difficulty, fiscal penalties may well have only a perverse effect. If a country has violated guidelines by running excessive deficits, it probably sees itself as in fiscal

${ }^{3}$ I am grateful to Tom Sargent for providing me with this reference. 
distress. Its reaction to strong fiscal penalties from the EMU might be to consider more seriously the alternative of exiting the EMU. Exiting and devaluing could restore fiscal balance.

But once we contemplate exit from the EMU and devaluation, it is no longer realistic to think of the debt of all countries as homogeneous. Investors who saw a possibility of a country's leaving EMU and devaluing would attempt to unload that country's debt. A ECB committed to a single interest rate on all member countries' government debts would be forced to buy up the fiscally weak country's debt and then, if devaluation did ensue, to absorb all the resulting capital losses. It seems unlikely that this would actually happen, and indeed much discussion of EMU does assume that government debt instruments of different countries would carry different rates, reflecting differing default risks. Economists who argue that there is no need for fiscal rules, that market discipline will enforce responsible fiscal policies, have in mind the development of varying default premia. It is thought that governments with unsustainable fiscal policies will face high interest rates, compensating for default risk, which will in turn force them to bring fiscal policies back into balance.

There cannot be default risk premia in a world where the probability of default is zero, however. The notion of market discipline to enforce responsible fiscal policy therefore requires that we contemplate default. But in EMU, default is unlikely to take the form of government debt being repudiated or marked down in value. Much more likely, at least in the early years of the Union, would be exit from the EMU and devaluation. The consequences of default would probably more severe than the consequences of exit from the EMU. But if this is the nature of the EMU - a collection of countries with varying probabilities of exit and devaluation - it is not very different from systems of linked exchange rates, of which we have a number of historical examples. It is well known that such systems are subject to sudden collapse if there is a real chance that members may abandon the preset parities.

The EMU is often compared to the United States. The US Federal Reserve System has no fiscal rules for US states. The states nonetheless do not generally run large fiscal deficits. There are differences across states, based on their fiscal situation, in the interest rates the market delivers for state government debt. Why should EMU not behave in the same way?

The US states have no recent experience with, and do not have a legal option of, issuing their own currency and devaluing it relative to the US dollar. One does find some differences in interest rates on state debt, but the differences are for the most part modest, and there are no examples of speculative attacks on state government debt leading to devaluation. \#\#\#\#\#\#\#\#\#\#\#

[To be expanded soon.]

\section{Theory for One Country, with Interest-Bearing Government Debt Only}

The logic of price determination through fiscal policy may be best appreciated in an extremely lean model. We include no stochastic elements, we assume there is no money, and we assume that there is no capital accumulation. There is, however, nominal government debt, which individuals perceive as giving them an option of shifting consumption through time. The price level is defined as the number of units of mature government bonds required to purchase a unit of the single commodity. While the absence of money is unrealistic, it helps to make clear how the price level can be set, and how it can become unstable, in situations where the role of money in the economy is small, or could become small in the presence of high inflation. The main results 
are that a policy of committing to a fixed primary surplus and a fixed nominal interest rate robustly guarantees a unique determinate price level, and that a more conventional policy of increasing the nominal interest rate in response to inflation, and increasing the primary surplus in response to increased real debt, does not deliver a determinate price level.

We assume a representative agent who maximizes

$$
\int_{0}^{\infty} \frac{C_{t}^{1-\gamma}}{1-\gamma} e^{-\beta t} d t
$$

with respect to $C$ and $B$ subject to

$$
\begin{gathered}
C+\frac{\dot{B}}{P}+\tau=\frac{r B}{P}+Y \\
B \geq 0 .
\end{gathered}
$$

Equation (2) is the usual budget constraint, equating consumption, asset accumulation, and taxes to the yield on wealth and exogenous non-asset income $Y$. Note that it is not a "jump" equation: the time-derivative appearing in it is both a left and right derivative. $B$ can change only over time, via a gap between income and expenditure. The inequality (3) requires that individuals not borrow from the government. Restrictions weaker than (3) would also work, but some such condition preventing individuals from financing arbitrarily large $C$ by rolling over debt (negative $B)$ forever is required.

The government's instantaneous budget constraint is

$$
\dot{B}=r B-P \tau \text {. }
$$

The government can be thought of as choosing $r, B$ and $\tau$ subject to (4), with $P$ taken as given, or it can be thought of as choosing all variables in the system subject to (4), (2) and private optimizing behavior. To close the model we need two more equations characterizing government policy. For example, one of these equations can be a tax-setting, or fiscal policy, equation, while another is an interest-rate-setting, or "monetary" policy equation.

Equations (2) and (4) imply the social resource constraint, which is simply

$$
C=Y \text {. }
$$

We define the real interest rate as

$$
\rho=r-\frac{\hat{\dot{P}}}{P},
$$

where the "hatted" time derivative in (6) is a right-derivative, referring to expected inflation from now on.

\section{A. The Private Agent's Problem}

First order conditions for the private agent are

$\partial C:$

$$
C^{-\gamma}=\lambda \text {. }
$$


$\partial B:$

$$
-\frac{\hat{\dot{\lambda}}}{P}+\frac{\lambda}{P} \frac{\hat{\dot{P}}}{P}+\beta \frac{\lambda}{P}=r \frac{\lambda}{P} .
$$

Substituting and manipulating the result, we obtain

$$
\gamma \frac{\hat{\dot{C}}}{C}=r-\frac{\hat{\dot{P}}}{P}-\beta .
$$

In the first examples below we will maintain the assumption that $Y$, and hence in equilibrium (via (5)) $C$, is constant, which implies via (9) and (6) that $\rho=\beta$.

\section{B. Pegging the Real Primary Surplus and the Nominal Interest Rate}

Suppose policy fixes the primary surplus as a constant $\tau=\bar{\tau}$ and the nominal interest rate as a constant $r=\bar{r}$. We can see from (9) that with $C$ constant,

$$
\bar{r}=\beta+\frac{\hat{\dot{P}}}{P} .
$$

This means that

$$
P_{t}=P_{0} e^{(\bar{r}-\beta) t},
$$

for some initial $P_{0}$. We can rewrite the government budget constraint (4) as

$$
\dot{B}=\bar{r} B-\bar{\tau} P_{0} e^{(\bar{r}-\beta) t} .
$$

This is an unstable linear difference equation, whose general solution is

$$
B_{t}=\frac{P_{0} e^{(\bar{r}-\beta)} \bar{\tau}}{\beta}+\kappa e^{\bar{r} t},
$$

where $\kappa$ is some constant. Dividing through by $P$, we get

$$
\frac{B}{P}=\frac{\bar{\tau}}{\beta}+\frac{\kappa e^{\beta t}}{P_{0}} .
$$

Thus the only value for $P$ at $t=0$ that is consistent with real government debt not exploding exponentially at the rate $\beta$ is the $P_{0}$ that satisfies (14) at $t=0$ with $\kappa=0$, i.e.

$$
\frac{B_{0}}{P_{0}}=\frac{\bar{\tau}}{\beta} .
$$

In words, the initial price level must adjust to make the real value of the outstanding nominal debt equal to the discounted present value of future net surpluses.

But how do we know that $B / P$ could not explode exponentially in equilibrium? We can rule out $\kappa<0$ by the fact that, from (14), we can see that this implies that $B$ would eventually become negative, violating the no-borrowing constraint on individual behavior. Individuals would therefore see themselves as not having enough resources to finance the $C=Y$ consumption level 
and also pay their taxes. This would generate an attempt to save, driving down the price level. If $\kappa>0$, real debt grows without bound. An individual who is accumulating wealth at this steady rate $\beta$ will see him or herself as able to increase consumption at all dates by, say, $\frac{\beta \kappa}{2 P_{0}}$. The individual, using his or her budget constraint to calculate the effects of this increase in $C$, would conclude that debt would no longer follow (12), which is an implication of the individual's budget constraint under $C=Y$, but instead would follow

$$
\dot{B}=\bar{r} B-\bar{\tau} P_{0} e^{(\bar{r}-\beta) t}+P \cdot(Y-C)=\bar{r} B-\left(P_{0} e^{(\bar{r}-\beta) t}\right)\left(-\frac{\beta \kappa}{2 P_{0}}-\bar{\tau}\right) .
$$

This is another unstable linear difference equation. Its general solution is, analogous to (14),

$$
\frac{B}{P}=\frac{\bar{\tau}}{\beta}+\frac{\kappa}{2 P_{0}}+\frac{\xi e^{\beta t}}{P_{0}}
$$

Because this equation, for a potential time path of an individual's debt perceived by the individual as possible, must satisfy the same initial condition as the equilibrium for the economy, it must imply the same $B_{0} / P_{0}$. Equating (14) and (17) at $t=0$ implies $\xi=\kappa / 2>0$, i.e. that wealth in the form of government debt still grows exponentially forever, despite the higher consumption. It is easy to see that this would be true so long as the amount of the increase in the constant level of consumption remains no higher than $\kappa / P_{0}$.

We can conclude, therefore, that only the solution in which the initial price level satisfies (15) is an equilibrium: If $P_{0}$ is lower than that, so initial wealth is higher, the FOC's and constraints imply that wealth will accumulate forever, so rapidly that individuals would perceive the possibility of financing a permanent increase in $C$ out of their wealth; and if $P_{0}$ is higher than that, so initial wealth is lower, the FOC's and constraints imply that individual wealth will become negative in finite time, violating the solvency constraint on individuals (3).

Note that we did not arrive at the unique equilibrium here simply by "ruling out explosive solutions". There is an explosive component to the correct solution. Prices rise or shrink (depending on whether $\bar{r}>\beta$ or $\bar{r}<\beta$ ) exponentially in equilibrium, according to (11), and nominal debt $B$ must rise or shrink in proportion to $P$.

Note also that, though the initial debt level $B_{0}$ can be any positive number, it cannot be zero. This is because the budget constraint (12) then implies initial $\dot{B}<0$, which cannot occur when individuals have the solvency constraint (3).

Equilibrium in this economy displays a kind of "quantity theory of debt" determination of the price level. The higher the initial level of $B$, the higher the initial $P$, and $B$ and $P$ move in proportion to one another. In fact, if we set $\bar{r}=0$, we get an ordinary "quantity theory of money". With zero nominal interest rate, the "debt" in this model becomes in effect non-interestbearing money. Despite the absence of a transactions motive for holding money, people hold it because there is steady deflation at the rate $\bar{r}-\beta=-\beta$, making money an asset with an attractive return. The government maintains the deflation by taxing away a fixed proportion of the nominal 
stock of money per unit time. This causes prices to drop in parallel with the decline in $B$ (which in this case we may as well refer to as $M$ ), leaving real money balances $M / P$ constant.

\section{Committing to a Price Level}

Another kind of policy that guarantees a unique equilibrium price level consists of committing to a price level and at the same time instituting a fiscal policy rule that guarantees that new real debt is matched by future real taxes. A fiscal policy rule that accomplishes this is

$$
\tau=\phi_{0}+\phi_{1} \frac{B}{P}=\phi_{0}+\phi_{1} b
$$

where $b$ is real debt and $\phi_{1}>\rho, \phi_{0}<0$. To fix the price level, the government has to stand ready to trade the commodity for new debt at the fixed rate $P$. We do not in reality see monetary policies committed to intervening in goods markets to peg a price index, but we do see fixedexchange-rate regimes, which are in this one-commodity world the same thing. Notice that the policy we are considering here is an outright price peg - a commitment to trade matured debt for the commodity - not a commitment to adjust interest rates to enforce stable prices. The latter, if it is taken to imply raising interest rates when there is a threat of inflation, allows multiple unstable equilibria, as we have already seen.

The model's behavior with these policies is simple. With $P$ fixed, $r=\rho$. Substitution of (18) into the government budget constraint produces

$$
\dot{B}=r B-\phi_{0} P-\phi_{1} B=\left(r-\phi_{1}\right) B-\phi_{0} P,
$$

which is a stable equation in $B$ for fixed $P$, so that $B$ converges to $-\phi_{0} P /\left(\phi_{1}-\rho\right)$ from any initial condition.

This kind of equilibrium, however, is in some ways more fragile than the fixed- $r$, fixed- $\tau$ equilibrium of the preceding section. If we modify the fiscal rule by adding a random fluctuation in $\tau$, the effect on the previous section's equilibrium is negligible. In the Appendix we show that with a fixed- $r$, fixed- $\tau$ policy, if the randomness in $\tau$ is white noise, we still have constant $b$ in equilibrium, with the randomness in $\tau$ absorbed in perfectly correlated, offsetting fluctuations in $B$ and $P . \quad P$ follows a geometric random walk with drift. If we add the same type of randomness to the passive fiscal rule of this section, $b$ varies over time, with a variance several times larger than the per-period variance in the primary surplus itself.

Since the level of $b$ implies a certain level for average future primary surpluses, there may be upper bounds on politically tolerable levels of $b$. With white-noise $\tau$ and fixed $P, b$ is a Gaussian stochastic process that has no deterministic bound. This kind of policy is therefore inconsistent with there being any upper bounds on $b$.

A fixed- $P$ equilibrium can also be undermined by expectations that the commitment might not last. If there is a risk that policy may switch from the fixed- $P$ commitment to a fixed- $r$, fixed- $\tau$ policy corresponding to a higher price level, and if this risk increases with increasing $b$, interest rates start to rise even while the fixed- $P$ commitment is being maintained, accelerating the rise in $b$ and leading to a rapid collapse of the fixed- $P$ commitment. The Appendix lays out a version of this scenario in an explicit mathematical model. 


\section{Indeterminacy from Passive Fiscal Policy}

Economists sometimes have written as if it were clear that when governments issue new debt they are automatically committing themselves to the future taxes that will be needed to pay off the debt and interest on it. This is not true - governments can issue debt without any commitment to increased future taxes, and the result will be price inflation. But suppose a government is persuaded that it should commit to future taxes when it increases debt. One policy that has this effect sets the real primary surplus $\tau$ to respond positively to the level of outstanding real debt, as in (18). In order that (18) represent a commitment to paying the interest and principal on the real debt, we require $\phi_{1}>\beta$, i.e. the primary surplus increases by more than the increase in real interest rate payments as $B / P$ increases. It is easy to see that substituting this into the government budget constraint (4) produces

$$
\dot{B}=\left(r-\phi_{1}\right) B-P \phi_{0} .
$$

If we assume as before that interest rate policy simply pegs $r=\bar{r}$ at all times, we have the same class of solutions (11) for $P$ and (20) becomes a constant-coefficient linear differential equation, with general solution

$$
\begin{gathered}
B=e^{(\bar{r}-\beta) t} \frac{-\phi_{0} P_{0}}{\phi_{1}-\beta}+\kappa e^{\left(\bar{r}-\phi_{1}\right) t}, \text { or } \\
\frac{B}{P}=\frac{-\phi_{0}}{\phi_{1}-\beta}+\frac{\kappa e^{\left(\beta-\phi_{1}\right) t}}{P_{0}} . .
\end{gathered}
$$

Note that, under our assumption that $\phi_{1}>\beta$, and assuming also $\phi_{0}<0,(22)$ describes a stable time path for real debt, regardless of the initial price level. No initial price level can be ruled out as too low, as this condition does not imply ever-growing wealth for individuals, and none as too high because this condition does not imply that debt must become negative. The initial price level is indeterminate.

Leeper [1991] calls this kind of fiscal policy "passive", and he concludes that to guarantee uniqueness, it must be paired with an "active" interest rate policy, that is, one that aggressively increases the interest rate in response to inflation. A simple example of an active interest rate policy is one that sets

$$
r=\theta_{0}+\theta_{1} p,
$$

where $p=\log P$. Regardless of policy, the government budget constraint can be rewritten in real terms to produce

$$
\dot{b}=(\rho-(\dot{p}-\hat{\dot{p}})) b-\tau,
$$


where $b=B / P$. In a non-stochastic model like this one, the $\dot{p}-\hat{\dot{p}}$ term vanishes along the solution path. ${ }^{4}$ Then substituting (18) into (24) produces

$$
\dot{b}=\left(\rho-\phi_{1}\right) b-\phi_{0} .
$$

With $\phi_{1}>\beta=\rho,(25)$ is a stable differential equation. Now using the interest policy equation (23) and the real interest rate definition (6) to eliminate $r$, we arrive at

$$
\theta_{0}+\theta_{1} p=\beta+\dot{p}
$$

This is an unstable equation in $p$. It has the unique stable solution $p=\left(\beta-\theta_{0}\right) / \theta_{1}$. But the unstable paths for $p$ generate no violations of equilibrium conditions. The real rate of return remains fixed at $\rho=\beta$, even as the nominal rate diverges to $\pm \infty$. The real value of the debt converges exponentially toward its positive steady state value of $-\phi_{0} /\left(\phi_{1}-\beta\right)$, regardless of where it starts from, even though nominal debt explodes at ever-increasing exponential rates.

Thus, in contrast to what Leeper found, we find here that an active interest rate policy succeeds only in making it very likely that the price level will explode. It does not eliminate the indeterminacy that arises because (25) is a stable equation. The reader may wish to confirm that with the $\tau=\bar{\tau}$ policy of the previous section, an active interest rate policy like (23) leaves the initial price level determinate, while implying in general that the price level and nominal debt follow (more than exponentially) explosive paths.

The defect of a passive fiscal policy is that it implies fiscal stimulus when a surprise burst of inflation arrives. The surprise inflation makes real debt fall, and the passive fiscal policy then generates further inflationary pressure by reducing taxes, resulting in an inflationary spiral. The opposite sort of spiral arises when a surprise burst of deflation arrives. Leeper's conclusion that a passive fiscal policy is consistent with a determinate price level arises because he simply assumes that rapidly explosive paths of prices and interest rates are not possible. But as we see here, there are models in which such explosive paths are consistent with equilibrium. We will see below that adding a transactions motive for holding money does not necessarily alter this conclusion.

\section{E. A Balanced Budget}

In the US, the possibility of a policy that makes the conventional deficit constant is being discussed. In our notation this would be a policy of $\dot{B}=0$. This implies in turn

$$
r B=P \tau \text {. }
$$

Usually this policy is taken to be a prescription for taxes and expenditures, not a prescription that nominal interest rates on debt be kept low enough to maintain a zero deficit. So suppose we have an active interest rate policy like (23) to go with the balanced budget. As we have already observed, (23) implies that there is a unique initial price level consistent with non-explosiveness of the price level. This will imply a unique initial $r$ from (23), and then from (27) and the given initial

${ }^{4}$ Except in the sense that at the initial date $p$ may jump, so that in a sense $\dot{p}-\hat{\dot{p}}$ may have a discrete spike at time zero. 
value of $B$ a unique initial tax level $\tau$. Explosively decreasing $p$ implies, because $B$ is fixed, explosively increasing $B / P$. As we have discussed before, this is inconsistent with individual optimization. But explosively increasing $p$ implies for $B / P$ only a time path explosively decreasing toward zero. (The fact that it is $\log p$ that decreases exponentially, becoming negative, means that $P$ itself only shrinks toward zero, remaining positive.) This does not violate individual optimality conditions and it leads to no violation of solvency constraints. Thus a conventional balanced budget policy, even coupled with active interest rate policy, leads to indeterminacy of the price level. It rules out low prices followed by explosive deflation, but not high initial prices followed by explosive inflation.

We could, however, couple (27) with an active fiscal policy like $\tau=\bar{\tau}$. This converts (27) to a prescription for setting interest rates to balance the budget. Using the definition of the real rate and its constancy in equilibrium, we find that (27) becomes

$$
\dot{p}+\beta=\frac{P \bar{\tau}}{B} .
$$

While not a linear differential equation, this is an unstable equation in $P$ with a unique constant solution: $P=\frac{B \beta}{\tau}$. We might be tempted to conclude that (28) will once again generate upwardly explosive $P$ paths when initial $P$ is too high that are nonetheless consistent with equilibrium. However, this nonlinear equation can be solved analytically to imply some interesting behavior. Rewriting it, we can find

$$
\frac{\dot{P}}{P \cdot\left(P \frac{\tau}{B}-\beta\right)}=1
$$

We can expand the left-hand side in partial fractions and integrate, obtaining (when $P \tau / B>\beta$ )

$$
-\frac{1}{\beta} \log P+\frac{1}{\beta} \log \left(P \frac{\tau}{B}-\beta\right)=t+\kappa,
$$

where $\kappa$ is a constant of integration. Exponentiating both sides, we arrive at

$$
\frac{P \frac{\tau}{B}-\beta}{P}=e^{(\kappa+t) \beta}
$$

Since its left-hand side is bounded above by $\tau / \beta$ for positive $P,(31)$ implies that from any initial value of $P$, we reach infinite $P$ in finite time. That is, when the initial $P$ is above its steady-state value, inflation must be so explosive that the price level goes to infinity in finite time.

How do we interpret this result? The problem is that to characterize behavior properly we need to consider policy behavior after the date at which $P$ becomes infinite. But (27) becomes a nonsense equation with $P$ infinite. If we interpret $P=\infty$ as implying that there is no debt on which to pay interest, then the commitment to $\tau=\bar{\tau}$ is incompatible with a balanced budget after $P$ becomes infinite. One has to complete the model with a specification for policy in this posthyperinflation period. If we simply say that $\tau$ drops back to zero when $P$ reaches infinity, then 
there is indeterminacy - essentially the initial real value of the debt can be larger or smaller depending on how long there is before $P$ reaches infinity, and hence how long there is for the $\tau=\bar{\tau}$ policy to be sustained. If we suppose instead that the government will drop the balanced budget policy after $P$ reaches infinity, maintaining a conventional surplus and $\tau=\bar{\tau}$ even after the real debt has evaporated, private agents will see themselves as needing to borrow at this point to pay taxes. Anticipating this, they will feel insolvent earlier, save more, and thereby reduce the price level to that consistent with non-explosive equilibrium.

\section{Connecting the Single-Country Models to Facts}

These models are obviously very simple and stylized, but they display behavior that matches some aspects of what we see in real economies. Fixed exchange rate commitments do often unravel. The price level does seem to drift rather than to return to a constant equilibrium level. In a world where there are practical bounds on primary surpluses and unpredictable disturbances to fiscal balance, the models explain why unraveling price level commitments and drifting price levels might tend to emerge. A commitment to a stable price level can easily turn out to be unsustainable, and doubts on the part of the public about its sustainability will speed the commitment's unraveling. A commitment to fixed $\tau$ and fixed $r$ is more easily sustained. Of course real debt $b$, nominal interest rates $r$, and primary surpluses $\tau$ are not constant in real economies. A model that could even approximately match their actual behavior would have to allow for $\tau$ being, say, a stationary stochastic process, perhaps scaled by output $Y$, and for the tendency of monetary authorities to raise interest rates in reaction to inflation (though not in reaction to deviations of $P$ from a permanent target level).

The models do not treat one important and interesting aspect of fiscal policy: the question of what constitutes government debt. If private or sub-national governmental institutions can issue debt, and if they are "too big to fail", the national treasury may end up in effect backing the debt of these institutions with national taxes. The fiscal approach to price level determination makes it clear why such a situation threatens sudden changes in the exchange rate or the price level. As the circumstances that would trigger government assumption of large amounts of private debt begin to appear more likely, the chances of a sudden increase in government debt, without a corresponding commitment to higher future primary surpluses, become greater. This will in itself tend to increase the price level, or else to increase interest rates on government debt in anticipation of a price level increase in the future. If interest rates rise without accompanying increased inflation, debt increases more quickly, increasing expectations of a price rise.

\section{A Monetary Union}

One approach to analysis of monetary union ${ }^{5}$ treats it as implying that debt of all countries is not only denominated in the same units, but is also default-free and therefore indistinguishable across countries, from the point of view of an investor. If in this situation the common central bank fixes a constant nominal interest rate $\bar{r}$, while the $k$ fiscal authorities $i=1, \ldots, k$ each set a fixed real primary surplus $\tau_{i}$, the model for the price level essentially reduces to that of section III. To make this clear formally, we must distinguish now between the holdings of debt by

${ }^{5}$ This approach is taken by Woodford [1996]. 
residents of country $j$, which we will call $B_{j}$, and the amount of debt issued by the government of country $j$, which we will call $H_{j}$. Since in this environment all countries' debt securities are equivalent as assets, there is no need for $B_{j}$ and $H_{j}$ to match up. We maintain the assumption of lump-sum taxation, and the assumption that citizens of country $j$ pay all the taxes levied by government $j$, and no other taxes. Woodford [1996] adopts a different approach, assuming a single representative world consumer, as would be justifiable if risk sharing were complete. In doing so, he implicitly breaks the connection between a consumer's budget set and the stream of taxes in the consumer's country of residence. The difference in approach has little effect on the formal model in this section, but does affect interpretations of it.

Individuals in country $j$ have exactly the optimization problem laid out in (1)-(3) above, except with $j$ subscripts on $C, B$, and $\tau$ (but not on $P$ or $r$ ). The single-period government budget constraint for country $j$ is now

$$
\dot{H}_{j}=r H_{j}-P \tau_{j} .
$$

It is a market-clearing condition that ${ }^{1}$

$$
\sum_{j} H_{j}=\sum_{j} B_{j}
$$

Summing individual budget constraints therefore allows us to conclude that

$$
\sum_{j} C_{j}=\sum_{j} Y_{j} .
$$

Note, though, that because we allow people to buy and sell bonds internationally, it is not necessarily true country by country that $C_{j}=Y_{j}$.

\section{A. Pegging $r$ and all the $\tau$ 's}

Let us now assume as before that all the $Y_{j}$ 's are constant and consider a policy that fixes $\tau_{j}=\bar{\tau}_{j}>0$, all $j$, so that each country is committed to some fixed positive level of government surplus. If we combine these fiscal policies with a monetary policy that fixes $r=\bar{r}$, we can almost exactly as before arrive at the conclusion that a unique equilibrium price level exists. Equation (9) will still hold for each $C_{j}$ separately, though its right-hand side is common across all $j$ 's. Therefore all $C_{j}$ 's will grow at the same rate in equilibrium, and by (34) and the constancy of the $Y_{j}$ 's, all the $C_{j}$ 's are constant. By the same argument we made in the paragraph below (15) above, we can conclude that $B_{j} / P$ must remain bounded, for each $j$, along an equilibrium solution path. That is, for each individual in country $j$, it must be true on the equilibrium path that the discounted present value of consumption matches the discounted present value of $Y_{j}-\bar{\tau}_{j}$ plus the initial value of wealth. To connect this condition to the amount of debt issued, however, we have to aggregate over $j$ so as to be able to use (33). The aggregate instantaneous fiscal constraint analogous to (25) is 


$$
\sum_{j} \frac{\dot{H}_{j}}{P}=\rho \sum_{j} \frac{H_{j}}{P}-\sum_{j} \bar{\tau}_{j} .
$$

Because each $B_{j} / P$ must not explode, their sum, which is the sum of the $H_{j} / P$ 's, also must not explode, and this implies that the unstable difference equation (35) has the unique stable solution

$$
\sum_{j} \frac{H_{j}(0)}{P(0)}=\rho \sum_{j} \bar{\tau}_{j}
$$

which determines a unique initial price level.

It is not hard to see that this model behaves just as if the countries were aggregated into a single country, with a single aggregate GBC as well as a single interest rate policy and price level. We will not go through in detail the argument that when each country's government follows a passive fiscal policy, like (18) but with $j$-subscripts, the price level is indeterminate. The argument has the same structure as in the one-country case.

It might appear at this point that we have shown that all the attention to fiscal convergence in the debate over the EMU is unnecessary. The only constraint on fiscal policy that is required is that each country be committed to some level of positive primary surplus. Then an interest-ratepegging policy will work for the ECB as it works for an individual country central bank.

But this type of equilibrium has several drawbacks as a policy prescription. We get a preliminary indication of this when we observe that actually, it is not even required that each country be committed to a positive primary surplus. It is only required that the sum of the constant primary surpluses be positive. Some countries could run permanent primary deficits. Who is to decide who gets to run a permanent deficit? And the problem is deeper than that. We have not used, in deriving the equilibrium, any individual-country intertemporal government budget constraints. ${ }^{6}$ Indeed, if the $\bar{\tau}_{j}$ 's are set in no exact relation to the initial values of $H_{j} / P$, then in general all the individual country real debt time paths will be explosive, even though the debt holdings of individuals in each country remain bounded. Because we have assumed that individuals have no control over their governments, no conditions of individual rationality are violated by this situation. A country whose initial $H_{j} / P$ exceeds its $\bar{\tau}_{j} / \rho$ will have exploding debt, corresponding to the fact that its primary surpluses do not cover interest on its debt. This government behavior must be balanced by the presence of other governments whose surpluses more than cover interest on their debts. A country whose citizens have an initial $B_{j} / P$ exceeding

\footnotetext{
${ }^{6}$ Bergin1977 has analyzed a model like this imposing intertemporal budget constraints on all governments. Woodford argues that this is incorrect, since the country government budget constraints cannot be derived from optimizing behavior by private agents. However, since the behavior of governments that accumulate arbitrarily large amounts of debt of other governments is so contrary to the interests of their citizens, and the gains to their citizens if the government abandons the policy grow steadily over time as the wealth accumulates, it does seem interesting to examine the implications of assuming individual-government budget constraints, even for otherwise non-optimizing governments.
} 
that country's $\bar{\tau}_{j} / \rho$ will be able to support a $C_{j}$ in excess of its $Y_{j}$, indefinitely. This behavior must be balanced by other countries whose consumption is permanently below their endowment stream. The equilibrium initial price level adjusts initial consumer real debt holdings so that the amount of consumption in excess of endowments exactly balances the amount below endowments, while at the same time the amount of taxation in excess of interest obligations of the government exactly offsets the amount of taxation that falls short of government interest obligations.

As soon as we begin to think about the political economy of this equilibrium, we realize it is unstable. Each government can increase the welfare of its citizens in equilibrium by committing to a lower, or even a negative, $\bar{\tau}_{j}$, if the other countries' governments are presumed to hold their policies fixed. At any date along an equilibrium path, a surprise announcement by one country, that it was now committed to a new, lower level of $\bar{\tau}_{j}$ (that still left the sum of the $\bar{\tau}_{j}$ 's positive) would result in a new equilibrium with an initial upward jump in the price level and a permanent shift in consumption flows toward the country making the cut in primary surplus. If governments are elected, or for any other reason care about the welfare of their citizens, it will be difficult for them to maintain a commitment not to cut their primary surpluses. It seems likely that this would be especially true of those governments with higher primary surpluses relative to their initial stocks of outstanding debt. These governments will eventually become net creditors, with exponentially expanding stocks of real wealth in the form of government bonds. Political pressure to spend some of this accumulation of wealth on the citizenry would become enormous.

Note that the temptation to the governments here is much worse than the usual type of temptation to inflate for short run Phillips-Curve gains at the cost of long run damage. In such Phillips-Curve models, the government's temptation depends on its not putting proper weight on negative future consequences of its policy actions. The problem is to coordinate the government with its own future self or future replacements. In the multiple-country version of the model we are considering here, inflationary fiscal initiatives produce permanent, not temporary, real benefits to a country's citizens by transferring wealth to them from other countries. And the problem is to coordinate policies across governments of different countries, not different governments of the same country.

A dynamic game with a structure very close to what would be obtained from the model considered here if fiscal authorities took the fixed-r monetary policy as given and acted with incomplete information, non-cooperatively, and in the best interests of their constituents, is presented in Zarazaga [1997]. He shows that it can produce an equilibrium with steady high inflation alternating with brief episodes of extremely high inflation, much like what has actually been observed in several Latin American economies.

\section{B. A Politically Robust Fiscal Rule}

One might imagine an institutional structure that aimed to match $\bar{\tau}_{i}$ to $\rho H_{i}$ in each country initially and then monitored closely, with effective punishments, to insure that countries stuck to the initial commitment for $\bar{\tau}_{i}$. However any temporary random deviation of actual net surplus below the initial commitment level would generate gains for the deviating country. Simply requiring that the surplus return to the initial commitment level would not dissipate the gains from 
the deviation, so the temptation to "err" in the direction of producing actual $\tau_{i}$ below the agreed $\bar{\tau}_{i}$ would be great.

It might seem that a solution would be to require that any deviation of $\tau_{i}$ below target generate a requirement for higher surpluses thereafter, to offset any gains to the deviating country. For example, one might simply require each country to follow a fiscal rule of the form

$$
\tau_{j}=\phi_{0}+\phi_{1} \frac{H_{j}}{P} .
$$

As we know from our discussion of the similar (18) above, this will, if $\phi_{1}>\rho$, guarantee that each country's real debt is stationary around a target level. It will no longer be possible to permanently duck fiscal burdens by running temporary deficits. Any decline in the real primary surplus generates an offsetting requirement for even larger increase in it later. Monitoring such a rule would be easier, as it eliminates the possibility of shifting tax burden to other countries by "erring" in the setting of $\tau_{i}$.

However, if all countries follow a rule like (37), the aggregate tax rule takes the same form, and we are back in the situation of indeterminacy generated by passive fiscal policy. What is needed is a rule that can be monitored easily to ensure that countries cannot pass fiscal obligations to other countries by running deficits, yet maintains a commitment to a fixed level of aggregate primary surplus. This can be accomplished by requiring country taxes to respond, not to the level of the country's own real debt, but to the deviation of its share of aggregate real debt in the monetary union from a target level. That is we require that each country follow a fiscal rule of the form

$$
\tau_{j}=\phi_{0}+\phi_{1}\left(h_{j}-\theta_{j} h\right),
$$

where $h_{j}=H_{j} / P, h=\sum h_{j}$. We choose $\sum \theta_{j}=1$ and $\phi_{1}>\beta$. If we substitute (38) into the individual real budget constraints

$$
\dot{h}_{j}=\rho h_{j}-\tau_{j},
$$

we obtain a system with a single unstable root, corresponding to the aggregated budget constraints, and $n$ - 1 stable roots corresponding to the deviations of the country $h$ 's from their target shares. Such a rule would preserve the determinacy of the price level, yet would be easily monitored to insure that no country shifts fiscal burden to others.

This proposed class of rules is substantially different from the Maastricht fiscal criteria for the EMU. The Maastricht criteria set targets for conventional deficits relative to GDP and for debt relative to GDP. As in our single-country example above, the use of conventional deficits rather than real primary surpluses to set targets is a potential source of instability. The same is true of the use of fiscal rules that set fixed targets for real debt and adjust surpluses in response to deviations from the target.

\section{Price-Level Targeting}

We observed in section IV.C above that price level targeting, together with a fiscal rule adjusting the primary surplus in response to deviations of real debt from a target, could provide a 
uniquely determined price level. But while this idea may be useful for unions of small countries who can interpret a "price peg" as a peg to a fixed exchange rate with a strong international currency, it does not seem practical for the EMU. Intervening directly in commodity markets to influence prices would be a complex operation, since so many markets would have to be involved. It would also make the ECB's operations less transparent than are usual asset-market operations in government securities and more subject to political pressure. Probably for all these reasons, this form of a price-level commitment is not seen in existing monetary policies.

Furthermore, as we observed in IV.C, commitment to a price level is always subject to sudden collapse, if there is any chance of the associated fiscal rule forcing surpluses to unsustainable levels.

\section{Adding Money}

[Still to be added. In economies where barter is infeasible, so that with real balances zero utility is minus infinity, active interest rate policies, or fixed nominal money policies, sometimes deliver unique equilibria. However, if transactions costs are bounded even as real balances approach zero, then generally the model behaves like the models above without money. Fixed- $r$, fixed- $\tau$ policies still always deliver unique, stable price paths. If you want to get a more concrete idea of how it works out before this section is written, see Sims [1994].]

\section{REFERENCES}

Aiyagari, R. and M. Gertler [1985]. "The Backing of Government Debt and Monetarism," Journal of Monetary Economics 16, 19-44.

Bergin, Paul [1997]. "Price Level Determination in a Monetary Union", University of California at Davis discussion paper, available at http://polar.ucdavis.edu/ bergin/ (March).

Davis, Dewey [1936]. Financial History of the United States, twelfth edition, (New York, London, Toronto: Longmans, Green and Co.).

Kwan, Yum Keung and Francis T. Lui, "Hong Kong's Currency Board and Changing Monetary Regimes”, NBER working paper 5723, August 1996

Leeper, Eric M. [1991], 'Equilibria Under 'Active' and 'Passive' Monetary And Fiscal Policies," Journal of Monetary Economics 27, February, 129-47.

Sargent, T.J. and N. Wallace [1981]. "Some Unpleasant Monetarist Arithmetic," Quarterly Review of the Minneapolis Federal Reserve Bank, Fall, 1-17.

Schmitt-Grohë, Stephanie and Martin Uribe [1997]. "Price Level Determinacy and Monetary Policy under a Balanced-Budget Requirement", Board of Governors of the Federal Reserve System (April).

Sims, C. A. [1988]. "Identifying Policy Effects", in Empirical Macroeconomics for Interdependent Economies, Ralph Bryant et al., eds., Brookings 1988, pp. 305-321. 
Sims, C. A. [1994]. "A Simple Model for Study of the Determination of the Price Level and the Interaction of Monetary and Fiscal Policy," Economic Theory 4, 381-399.

Woodford, M. [1994]. "Monetary Policy and Price Level Determinacy in a Cash-in-Advance Economy," Economic Theory 4, 1994.

Woodford, Michael [1995]. "Price Level Determinacy without Control of a Monetary Aggregate," NBER Working Paper No. 5204.

Woodford, Michael [1996]. "Control of the Public Debt: A Requirement for Price Stability?" processed, Princeton University.

Zarazaga, Carlos E.J.M. [1997]. "Recurrent Hyperinflations in a Dynamic Game with Imperfect Monitoring in the Appropriation of Seignorage," processed, Federal Reserve Bank of Dallas. 


\section{APPENDIX}

Here we discuss the explicitly stochastic version of the model. The individual's budget constraint is still (2), essentially, but we now write it as a stochastic differential equation

$$
d B=(r B+P Y-P C) d t-P d \mathrm{~T},
$$

where $\mathrm{T}$ is cumulated real primary surpluses, so that the non-stochastic model in the text corresponds to the case $d \mathrm{~T}=\tau \cdot d t$. The agent treats $B$ as an endogenous state variable, $C$ as a control, and $P, Y$, the aggregate level of debt per capita $B^{*}$, and $\mathrm{T}$ as exogenously given stochastic processes. We assume that there is a vector $Z$, exogenous to the individual's decision problem, that characterizes the current values of and future distribution of the exogenous processes. The individual will then have a value function $V(b, Z)$, where $b$ is, as in the text, real debt $B / P$.

We consider three stochastic models. In all three, policy is the only source of uncertainty. In the first two, randomness is stochastically continuous, while in the third there is a single random policy switch, of uncertain timing, with policy otherwise deterministic.

In the first pair of models we see that serially uncorrelated randomness in taxes can, with a fixed- $r$ policy, be consistent with constant real debt and unchanging expected taxes, while with a passive, or Ricardian, fiscal policy and a commitment to a fixed price level, serially uncorrelated randomness in taxes leads to large swings in debt and, correspondingly, to expected taxes. In the third model we see exactly how a commitment to a fixed price level can break down if high debt levels lead to expectations of a regime switch. In the example, even though the timing of the breaking of the commitment is not known with certainty, debt explodes so fast, once it exceeds some critical value, that a finite upper bound to the time the fixed- $P$ commitment can last is known with certainty.

\section{A. Fixed $r$, primary surplus a constant plus white noise}

Policy in this example sets

$$
r=\bar{r} .
$$

The primary surplus is modeled as having a constant mean, but with a continuous time white noise component, which we think of as generated by uncontrollable short-run fluctuations in expenditures and revenue. We introduce the variable $\mathrm{T}$, cumulative primary surpluses, and specify that

$$
d \mathrm{~T}=\bar{\tau} \cdot d t+\sigma_{T} d Z,
$$

where $Z$ is a standard Wiener process. The budget constraint facing an individual is then

$$
d B=(r B-P \cdot(C+Y))-P d \mathrm{~T},
$$

and the government budget constraint is

$$
d B=r B \cdot d t-P d \mathrm{~T} .
$$

Using the notation that 


$$
d P=\hat{\dot{P}} d t+\sigma_{P} d Z,
$$

(which implicitly assumes that all randomness in $P$ arises from the randomness in $\mathrm{T}$ ) we can rewrite (43) as

$$
d b=\left(r b-b \frac{\hat{\dot{P}}}{P}+b \frac{\sigma_{P}^{2}}{P^{2}}-\frac{\sigma_{T} \sigma_{P}}{P}-C+Y-\bar{\tau}\right) d t+\left(\sigma_{T}-b \frac{\sigma_{P}}{P}\right) d Z
$$

Correspondingly we can rewrite the government budget constraint (44) as

$$
d b=\left(r b-b \frac{\hat{\dot{P}}}{P}+b \frac{\sigma_{P}^{2}}{P^{2}}-\frac{\sigma_{T} \sigma_{P}}{P}-\bar{\tau}\right) d t+\left(\sigma_{T}-b \frac{\sigma_{P}}{P}\right) d Z
$$

The Bellman equation for the private agent's optimization problem is therefore

$$
\begin{gathered}
\max _{C}\left\{U(C)-\beta V(b, X)+V_{b} \cdot\left(r b-b \frac{\hat{\dot{P}}}{P}+b \frac{\sigma_{P}^{2}}{P^{2}}-\frac{\sigma_{T} \sigma_{P}}{P}-C+Y-\bar{\tau}\right)+V_{X} \cdot \hat{\dot{X}}\right. \\
\left.\quad+\frac{1}{2} V_{b b} \cdot\left(\sigma_{T}-b \frac{\sigma_{P}}{P}\right)^{2}+\left(\sigma_{T}-b \frac{\sigma_{P}}{P}\right) V_{b X} \cdot \Sigma_{X}+\frac{1}{2} \Sigma_{X}{ }^{\prime} V_{X X} \Sigma_{X}\right\}=0
\end{gathered}
$$

The first-order condition with respect to $C$ is

$$
U^{\prime}(C)=V_{b}(b, X)
$$

and that with respect to $b$ (the envelope condition) is

$$
V_{b}\left(r-\beta-\frac{\hat{\dot{P}}}{P}+\frac{\sigma_{P}^{2}}{P^{2}}\right)-V_{b b}\left(\sigma_{T}-b \frac{\sigma_{P}}{P}\right) \frac{\sigma_{P}}{P}-V_{b X} \cdot \Sigma_{X} \frac{\sigma_{P}}{P}=-\frac{\hat{\dot{d}}}{d t} V_{b} .
$$

We now verify that there is a solution to the constraints and FOC's in which the individual's value function depends on $b$ alone (which is reasonable, because there is no exogenous state that influences the individual's envirionment). Since we know that in equilibrium $C=Y$, (49) tells us that $b$ will be constant if we have an equilibrium of the conjectured form.

In order for $b$ to be constant, both the stochastic and non-stochastic components of $d b$ must be zero. This allows us to conclude, from (47), that

$$
\sigma_{T}=b \frac{\sigma_{P}}{P}
$$

and

$$
b=\frac{\bar{\tau}}{r-\frac{\hat{\dot{P}}}{P}}
$$

Then using (50) we can conclude that 


$$
r=\beta-\frac{\sigma_{P}^{2}}{P^{2}}+\frac{\hat{\dot{P}}}{P}=\beta-\frac{\sigma_{T}^{2}}{b^{2}}+\frac{\hat{\dot{P}}}{P}
$$

Thus a constant- $b$ equilibrium is possible, and it implies constant $\sigma_{P} / P$ and constant $\hat{\dot{P}} / P$, i.e. that $P$ is a geometric random walk with drift. Solving (52) and (53) explicitly for the constant $b$ produces only one positive solution. For small values of $\sigma_{T}^{2}$, it is approximately $b=\bar{\tau} / \beta+\sigma_{T}^{2} / \bar{\tau}$. The corresponding inflation rate is approximately $\hat{\dot{P}} / P=r-\beta+\beta \sigma_{T}^{2} / \bar{\tau}$. Thus the constant equilibrium values of $b$ and expected inflation remain, for small $\sigma_{T}^{2}$, close to the values found in the deterministic model. ${ }^{7}$

\section{B. Fixed P, primary surplus a passive rule plus white noise}

Here we suppose that policy pegs $P$ and sets

$$
d T=\left(-\phi_{0}+\phi_{1} b\right) d t+\sigma_{T} d Z .
$$

This amounts to adding white noise $(d Z)$ error to the passive fiscal rule of (18). With this specification, (46) specializes to (because policy holds $\sigma_{P}=0$ and $\hat{\dot{P}}=0$ )

$$
d b=\left(r b+\phi_{0}-\phi_{1} b-C+Y\right) d t+\sigma_{T} d Z .
$$

The envelope condition also simplifies, allowing us to replace (50) with

$$
V_{b} \cdot(r-\beta)=-\frac{\hat{d}}{d t} V_{b} .
$$

Since we know that in equilibrium $C$, and hence $U$ and $V$, are constant, this lets us conclude that $r=\beta$. Then if, as in the deterministic model, we impose $\phi_{1}>\beta$, we obtain from (55) a stable stochastic difference equation for $b$,

$$
d b=\left(\left(\beta-\phi_{1}\right) b+\phi_{0}\right) \cdot d t+\sigma_{T} d Z .
$$

This equation implies, in stochastic steady state, a mean for $b$ of $\phi_{0} /\left(\phi_{1}-\beta\right)$ and a variance of $\sigma_{T}^{2} /\left(2 \cdot\left(\phi_{1}-\beta\right)\right)$. Notice that if $\phi_{1}$ is fairly close to $\beta$, as seems realistic, the short run variance in the surplus is amplified into much larger long run swings in $b$ and therefore $\tau$. With a mean delay for return of debt to its mean of 30 years $\left(\phi_{1}-\beta=.033\right)$, the long run variance in $b$ is 15 times the variance of the one-year primary surplus, $\mathrm{T}(t)-\mathrm{T}(t-1)$.

${ }^{7}$ It may seem paradoxical that in this model, where the real return on debt is stochastic, the interest rate emerges as less than the discount rate plus expected inflation. But this model, because it has constant, non-stochastic $C$, has no risk premia. The second-order effect of $\sigma_{P}$ on $r-\hat{\dot{P}} / P$ compensates for the fact that the return on debt depends on the growth in $1 / P$, not $P$. In fact, $r=\beta-P(\hat{\dot{d}} / d t)(1 / P)$. 


\section{Fixed $P$, passive $\tau$, with randomly timed shift to fixed $r$, fixed $\tau$}

The third stochastic model discussed in the text has $P$ constant at the value $\bar{P}$ and $\tau$ set according to (18), up until a random time at which policy switches to fixing $r=\beta, \tau=\bar{\tau}$, with $\bar{\tau}$ a random variable realized only at the time of the switch. The hazard rate for the switch is $\delta$, given by

$$
\delta=\theta_{0}+\theta_{1} b
$$

Here the Bellman equation takes a different form, so that (48) is replaced by, for the period before the switch,

$$
\begin{aligned}
\max _{C}\{ & U(C)-\beta V\left(b, b^{*}, 0\right)+V_{b}\left(b, b^{*}, 0\right) \cdot(r b-C+Y-\tau) \\
& \left.+V_{b^{*}}\left(b, b^{*}, 0\right) \cdot\left(r b^{*}-\tau\right)+\delta\left(b^{*}\right) E_{t}\left[V\left(\frac{\bar{b} b}{b^{*}}, b^{*}, 1\right)-V\left(b, b^{*}, 0\right)\right]\right\}=0
\end{aligned}
$$

where $b^{*}$ is aggregate per capita debt, $\bar{b}_{t}$ is what the equilibrium aggregate per capita debt will be after the switch in policy if the switch occurs at $t$, and the third argument of $V$ is an indicator variable $S$ taking on the value zero before the switch, 1 after. The FOC with respect to $b$ is

$$
V_{b}\left(b, b^{*}, 0\right)(r-\beta-\delta)+\delta \cdot E_{t}\left[D_{1} V\left(\frac{\bar{b} b}{b^{*}}, \bar{b}, 1\right) \frac{\bar{b}}{b^{*}}\right]=-\frac{\hat{d}}{d t} V_{b}\left(b, b^{*}, 0\right) .
$$

From the FOC w.r.t. $C$, which is here $U^{\prime}=V_{b}\left(b, b^{*}, 0\right)$, we know that the right-hand side of (60) is zero in equilibrium. Also, we know that after the switch, optimal behavior for an agent whose $b$ might possibly differ from the aggregate per capita level will be to set $C=Y+r b-\bar{\tau}$, and leave it there forever. This means that after the switch the value function is just

$$
V\left(b, b^{*}, 1\right)=\frac{(Y+r b-\bar{\tau})^{1-\gamma}}{(1-\gamma) \beta} .
$$

This lets us conclude directly that $U^{\prime}(Y)=V_{b}(\bar{b}, \bar{b}, 1)=V_{b}\left(b^{*}, b^{*}, 0\right)=Y^{-\gamma}$ in equilibrium. Using this in (60) reduces it to

$$
Y^{-\gamma}\left(r-\beta+\delta \cdot\left(\frac{E_{t} \bar{b}}{b^{*}}-1\right)\right)=0 .
$$

Since after the switch aggregate per capita real debt will be just $\bar{b}=\bar{\tau} / \beta$, we can use (58) and (62) to arrive at an expression for $r$ :

$$
r=\beta-\left(\theta_{0}+\theta_{1} b^{*}\right)\left(\frac{E \bar{\tau}}{\beta b^{*}}-1\right)
$$

Substituting this into the government budget constraint produces 


$$
\dot{b}=\left(\beta+\theta_{0}-\theta_{1} \frac{E \bar{\tau}}{\beta}-\phi_{1}\right) b+\theta_{1} b^{2}-\theta_{0} \frac{E \bar{\tau}}{\beta}+\phi_{0} .
$$

Let us label the three coefficients in the right-hand side of this equation $a_{0}, a_{1}$, and $a_{2}$, according to their degree. If $a_{0}>0$ and $a_{1}>0$, the right-hand side has no roots for positive $b$, and the equation therefore has no steady state. If $a_{0}<0$, the equation has one steady state at a positive $b$, but the steady state is unstable. For any initial $b$ above the steady state, $b$ explodes without bound, while for any below the steady state, $b$ shrinks steadily. In fact the policy specified is not feasible if the initial $b$ is below steady state, as it would have to drive $b$ below zero, which is not possible. If $a_{0}>0$ and $a_{1}<0$, there may be no steady state, but if there is one, there are two, both for positive values of $b$. That corresponding to the lower value of $b$ is stable, while the upper one is unstable. These situations are illustrated in Figure 1 through Figure 3.

Once $b$ is above the unstable equilibrium value, or when there is no stable $b>0, b$ eventually is bounded below by a solution to a differential equation of the form $\dot{b}=\kappa b^{2}$, with $\kappa>0$. Solution paths for equations of this form, if starting from positive $b$, always converge to infinity in finite time, so this must be true of $b$ as well. The economic mechanism for this rapid collapse of the fixed- $P$ commitment is familiar. High debt increases the likelihood of devaluation, raising interest rates, which in turn accelerates the rate of increase of the debt. Note that when, as in Figure 1 or Figure 2, the deterministic version of the model would yield an equilibrium point B with debt above the level sustainable after the policy switch, the unstable accelerating growth of debt occurs even for some values of $b$ below the level (given by point $\mathrm{A}$ in the figures) that can be sustained indefinitely after the policy switch. 


\section{Figure 1}

No Steady State

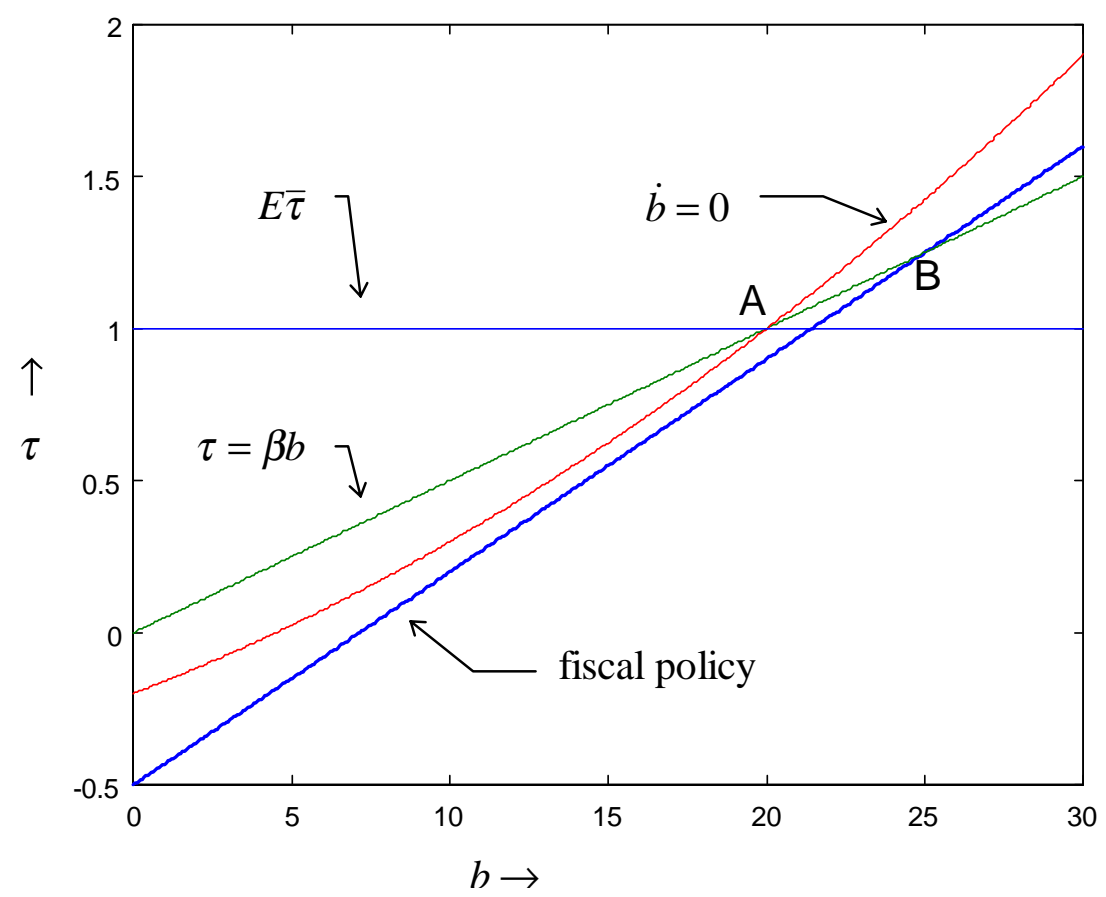

Notes: In all three figures point $\mathrm{A}$ is the crossover between $r<\beta$ and $r>\beta$. For higher $b$ there is a premium in the interest rate for expected inflation, and for lower $b$ interest rates are lowered by expected deflation. Point $B$ is what the equilibrium would be in the absence of any risk of policy switch $(\delta=0)$. Points $C$ are present only in the next two figures. They are the unstable and stable equilibria of the system, respectively. Parameter settings in Figure 1 are $\beta=.05$, $\theta_{0}=.01, \theta_{1}=.001, \phi_{0}=.5, \phi_{1}=.07, E \bar{\tau}=1$. 
Figure 2

Two Steady States

Critical $b$ less than $E \bar{\tau} / \beta$

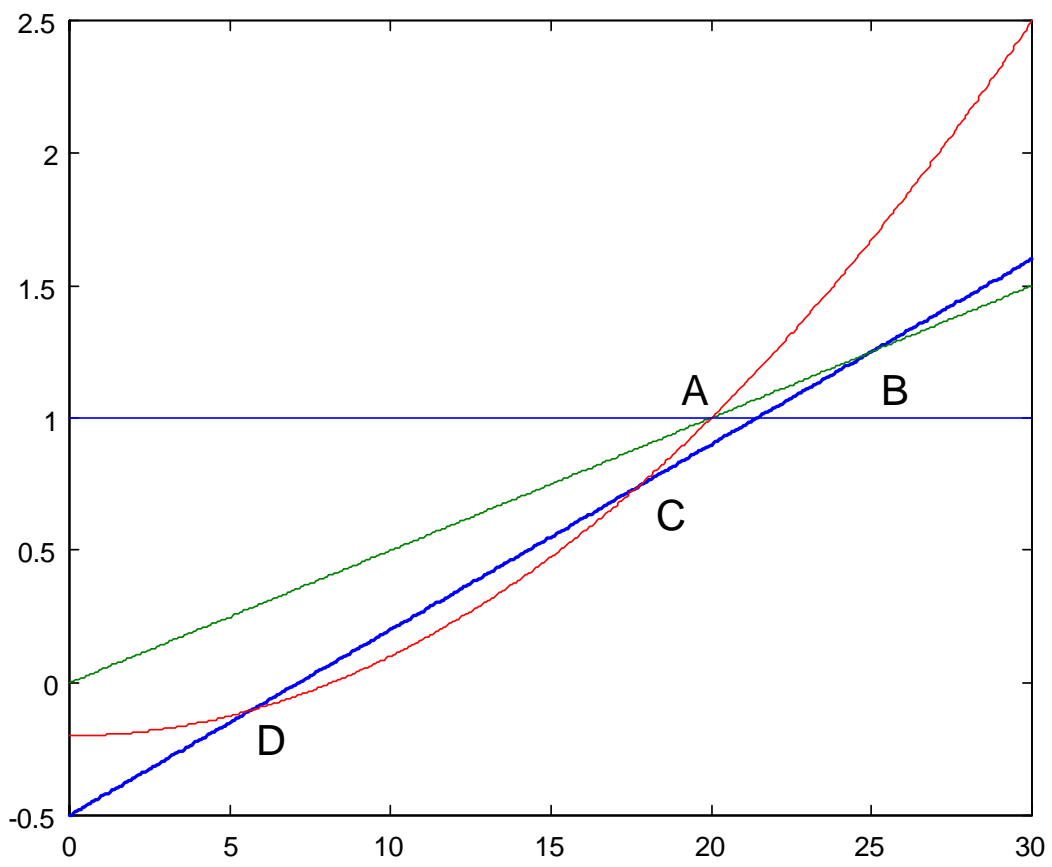

Notes: Parameter settings and labeling of points as in Figure 1, except that here $\theta_{1}=.003$. 
Figure 3

Two Steady States

Critical $b$ less than $E \bar{\tau} / \beta$

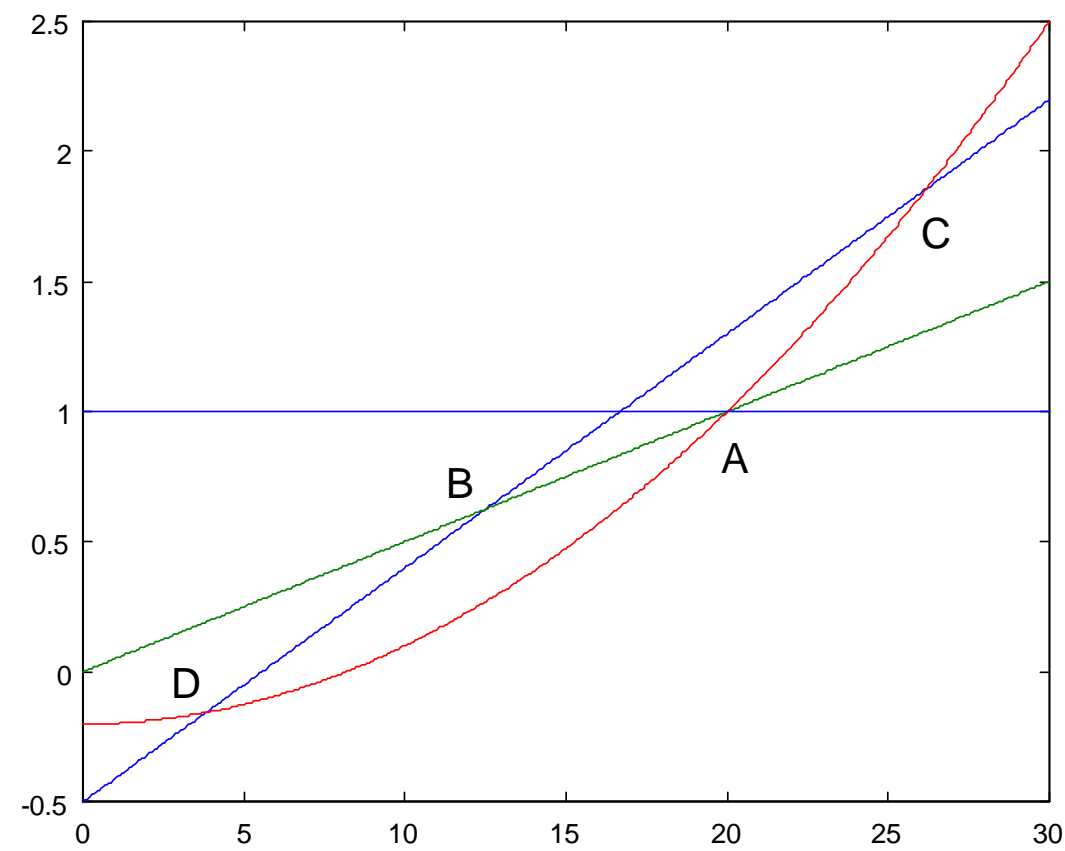

Note: Parameter settings and labeling of points as in Figure 2, except that here $\phi_{1}=.09$. 